\title{
Modern leadership and management methods for development organizations
}

\author{
Natalia V. Samosudova ${ }^{1, *}$ \\ ${ }^{1}$ Moscow State University of Civil Engineering, YaroslavskoyeShosse, 26, Moscow, 129337, Russia
}

\begin{abstract}
The following article represents an overview of the basic theoretical concepts of leadership and management in the framework of the organization. The main scientific approaches to leadership are described in conjunction with various leadership styles and their correlation with different levels of effectiveness as a result of the organization's activity. Certain characteristics applicable to leaders and managers are mentioned. Attitude and obligations of a modern construction project manager are discussed, along with the challenges the construction industry represents these days. Ideas about methods of complex analysis for further research and identifying leadership tactics and their impact on the success of the development organization are suggested.
\end{abstract}

\section{Introduction}

Modern science and practical activities in any field, construction industry included, still do not have an exact point of view regarding defining of terms "leadership" and "management" and their influence on the results of the organization's activity.

The quest for personality qualities typical for leaders has been going on for centuries. Qualitative characteristics, which have gradually become part of professional obligations now, are also important for top managers of development companies. The search for these attributes remains a considerable aspect of increasing productivity and the quality of construction organizations work.

Objectives of this research are:

- comparative analysis of various scientific approaches to theoretical aspects of leadership and management in construction and development organizations;

- identification of methods of giving specific meaning to terms "leadership" and "management";

- formation of exact definitions of these terms according to their specifics and the aim of getting better results of the organization's activity.

\section{Methodology}

\footnotetext{
*Corresponding authors: natalsamos@mail.ru
} 


\subsection{Basic Concepts}

Over the years, words "leadership" and "management" have, in the organizational concept, been used both as synonyms and completely different definitions. F.E. Fiedler, W.G. Bennis and J.W. Gardner suggested, respectively, that "leadership behavior means particular acts in which a leader engages in the course of directing and coordinating the work of his group members" [1], "the capacity to create a compelling vision and translate it into action and sustain it" [2], "leadership is the process of persuasion or example by which an individual (or leadership team) induces a group to pursue objectives held by the leader and his or her followers" [3]. M.M. Chemers, for instance, believed that "leadership is a process of social influence in which one person is able to enlist the aid and support of others in the accomplishment of a common task"[4]. V.H. Vroom and A.G. Jago defined leadership as "a process of motivating people to work together collaboratively to accomplish great things" [5]. According to J.C. Maxwell's theory, «management maintains and controls while leadership influences and creates opportunity for people to change and perform» [6].

B.M. Bass and al. divided leadership into 2 types: transactional leadership, based on exchange of labor for rewards, and transformational leadership, based on taking care of employees, intellectual stimulation, and providing a group vision. [7], [8].

Transactional leadership is focused on supervision, organization and productivity. Leaders using this style are primarily concerned with the quality of labor, distinguishing and correcting faults and deviations; they use reward and punishments to gain compliance from their followers. Transactional leaders are used to working within existing systems; they solve problems by thinking inside the box. They are not willing to change their attitude, which is not always a good thing for further development of the organization.

Transformational leadership, however, is represented by a leader who identifies existing issues and makes a difference, being supported by his followers. Transformational leadership serves to enhance the motivation, morale and job performance of followers through a variety of mechanisms, which include connecting the follower's sense of identity and self to a project and to the collective identity of the organization; being a role model for followers in order to inspire them and to raise their interest in the project. At the same time, the leader gains understanding of the strengths and weaknesses of followers, allowing him to align followers with tasks that enhance their performance [9].

\subsection{Trait Theory}

The search for the characteristics of leaders has continued for centuries. Certain qualities distinguishing an individual as a leader have been explored in philosophical writings from Plato's Republic to Plutarch's Lives, which shows us the early recognition of the importance of leadership centuries ago. The idea of leadership based on a complex of special qualities turned out to become the first solid leadership concept which is known as the "trait theory of leadership". It had been suggested that true leaders are not developed but born with a set of certain characteristics due to which they are able to improve their organizational skills and to fortify their position as leaders. These characteristics include appearance, personality traits, abilities and skills, legacy and social status. This approach is based on T.Carlyle's Great Men Theory, according to which history can be largely explained by the impact of "great men", or heroes - highly influential individuals who, due to either their personal charisma, intelligence, wisdom or political skill, utilized their power in a way that had a decisive historical impact [10].

The trait theory's main goal is to compile an ultimate list of qualities the ideal leader needs. R.M. Stogdill's research showed the importance of such traits as intellect, 
observation, concern for other people's needs, understanding of current circumstances, perseverance, drive, self-confidence and preparedness for taking responsibility [11]. However, after meeting some obstacles during the compilation process, Stogdill concluded that there's no universal set of traits applicable for every leader; characteristics vary depending on followers, circumstances, activity and ultimate goals. Mostly, it's quite difficult to determine whether one set of traits is better than another or not.

The 1980s' new research methods allowed researchers to review the trait theory. Statistical advances allowed them to conduct meta-analyses, in which they could quantitatively analyze and summarize the findings from a wide array of studies. This advent allowed trait theorists to create a comprehensive picture of previous leadership research rather than rely on the qualitative reviews of the past. Thereby, it was revealed that individuals can and do emerge as leaders across a variety of situations and tasks. Moreover, significant relationships exist between leadership and such individual traits as intelligence, adjustment, extraversion, conscientiousness, openness to experience and general selfefficacy [12-18]. Nonetheless, S.J. Zaccaro noted that trait theories are still concentrated on a small set of specific individual attributes, ignoring cognitive abilities, motives, values, social skills, expertise, and problem-solving skills whatsoever. Also, they fail to consider patterns or integrations of multiple attributes; they do not distinguish between those leader attributes that are generally not malleable over time and those that are shaped by, and bound to, situational influences; they do not consider how stable leader attributes account for the behavioral diversity necessary for effective leadership [19].

The trait concept has become the foundation of the majority of recruitment, hiring and promotion methods [20].

\subsection{Behavioral Theories and Leadership Styles}

Having considered the criticism towards the trait concept, theorists took a new path -- they began to regard leadership as a set of behavioral models. They appraised successful leaders' behaviors for identifying and classifying them into common groups of styles [21]. A leadership style is a complex of specific methods and techniques used by a leader. To be successful, a leader should not only know how to identify and utilize necessary leadership styles, but to be able to switch them in order to adjust the organization to the ever-changing circumstances. In 1939 K. Lewin, R.Lippitt and R.K. White developed one of the most widespread theories of correlation between leadership styles and employees' productivity levels [22]. They distinguished 3 common leadership styles: authoritarian, democratic, and laissez-faire. Under authoritarian, or autocratic leadership, all decision-making powers are centralized in the leader; he does not entertain any suggestions or initiatives from subordinates. Exactingness, strict supervision, discipline and result-orientation are dominant; any socio-psychological factors are neglected. Authoritarian style is quite effective for emergency situations, but it won't work in a long run.

Democratic leadership style, based on collegiality, initiative and trust, is oriented not only on the result, but on the methods of its achievement. Those who use this style tend to make a final decision only after making a consensus with subordinates. However, the majority's opinion may not always be the best option for solving particular problems, so this way of action may not lead to expected results. In Laissez-faire or free-rein leadership, decision-making is passed on to the subordinates. They are given complete right and power to make decisions to establish goals and work out the problems or hurdles. Such approach may take some time, but it proves to be quite useful if the team is devoted to the main goal and is ready to do what is best for the company. In 1964 American management theoreticians R.R.Blake and J.S.Mouton created the managerial grid model (Figure 1), which also falls within the framework of behavioral approach. It suggests five different 
leadership styles, based on the leaders' concern for people and their concern for goal achievement. Blake and Mouton concluded that the optimal style is 'Team', (9.9), as it involves high concern for both people and production. Managers choosing to use this style encourage teamwork and commitment among employees. This method relies heavily on making employees feel themselves to be constructive parts of the company.

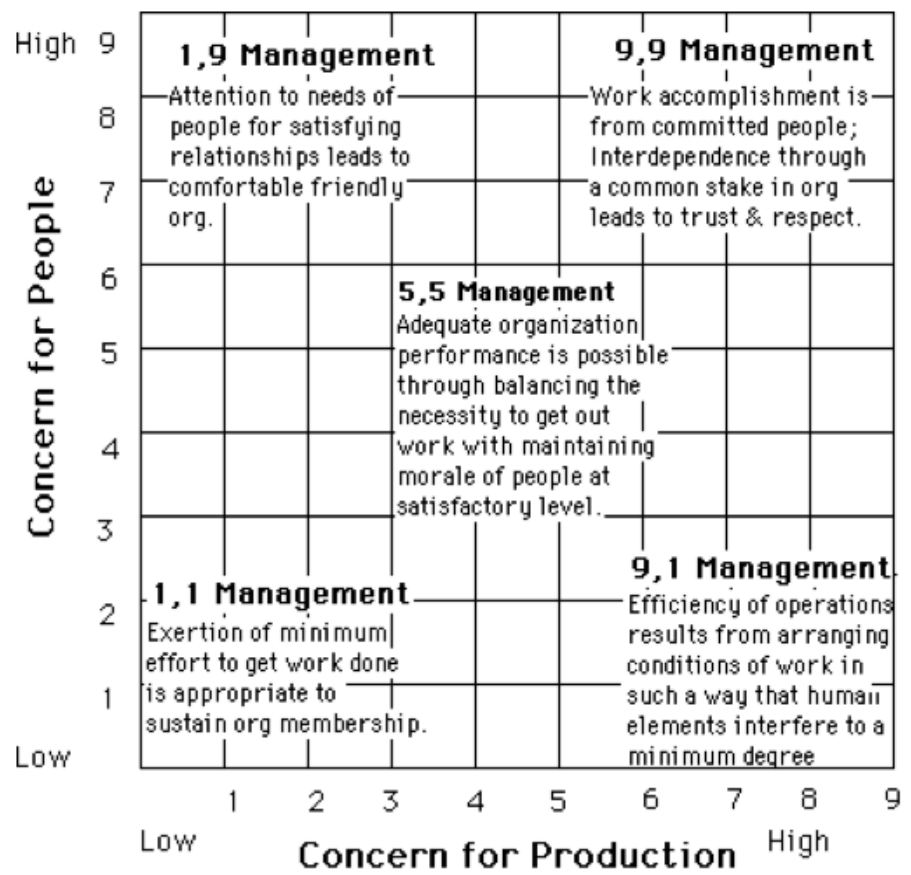

Fig. 1. Blake and Mouton's Managerial Grid.

Behavioral theory had become the basis of leadership style classification; it encouraged managers to look for the best behavioral model. Nonetheless, in 1960s this approach was perceived as limited, because it did not consider the impact of another important factors which defined management efficiency in various situations.

\subsection{Situational and Contingency Theories}

Situational theory also appeared as a reaction to the trait theory of leadership. In 194050sR.M.Stogdill [24] and R.D.Mann [25] found out that an individual who presents himself as a leader in one situation may not necessarily stay in this position in another circumstances. Ergo, leadership is no longer associated only with a set of particular personality qualities. Situational approach suggests that for various circumstances there is a need for various traits, therefore the universal psychographic portrait of the ideal leader simply does not exist. The leader's actions mostly depend on the details of the situation he is dealing with [26]. In other words, the leader should be able to change his behavior in order to adjust for diverse situations. Some theorists started to synthesize the trait and situational approaches. K.Lewin and his colleagues distinguished some cases for which various leadership styles worked best. For example, authoritarian style is extremely useful in periods of crisis but fails to be effective in day-to-day management; democratic style is more adequate in situations that require consensus building; finally, laissez-faire leadership style is appreciated for the degree of freedom it provides, but as the leaders do not "take charge", they can be perceived as a failure in protracted or thorny organizational problems. 
Thus, theorists defined the style of leadership as contingent to the situation, which is sometimes classified as contingency theory. Four contingency leadership theories appear more prominently in recent years: Fiedler contingency model, Vroom-Yetton decision model, the path-goal theory, and the Hersey-Blanchard situational theory.

The Fiedler contingency model (1964) was the first fundamental work in this field. It defined two types of leaders: those who tend to accomplish the task by developing good relationships with the group (relationship-oriented), and those who have as their prime concern carrying out the task itself (task-oriented) [1]. According to F.E. Fiedler, there is no ideal leader. Both task-oriented and relationship-oriented leaders can be effective if their leadership orientation fits the situation. When there is a good leader-member relation, a highly structured task, and high leader position power, the situation is considered a "favorable situation". Fiedler found that task-oriented leaders are more effective in extremely favorable or unfavorable situations, whereas relationship-oriented leaders perform best in situations with intermediate favorability. V.H. Vroom, in collaboration with P.W. Yetton (1973) and later with A.G. Jago (1988), developed a taxonomy for describing leadership situations, which was used in a normative decision model where leadership styles were connected to situational variables, defining which approach was more suitable to which situation. This system, called Vroom-Yetton contingency model, identifies five different styles (ranging from autocratic to consultative to group-based decisions) depending on the situation and the level of involvement (Figure 2). A leader answers seven "yes/no" questions and then uses a decision tree until he arrives at a code which identifies the best decision-making process for him and his team.

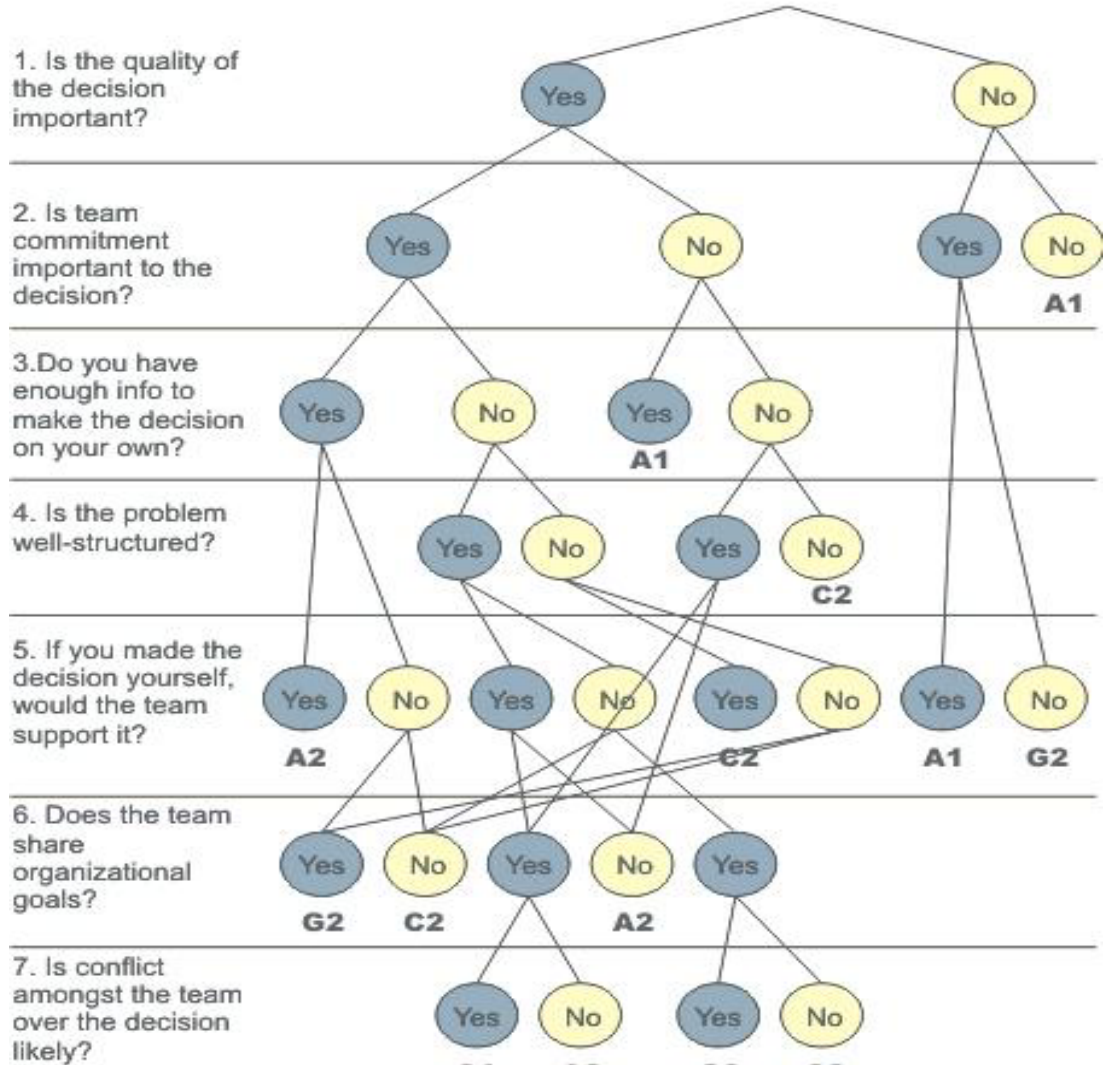

Fig. 2. Vroom-Yetton contingency model. 
In 1971 a psychologistR. House developed the path-goaltheoryof leadership, based on the expectancytheoryofV. Vroom [29]. According to thi stheory, a leader can use different leadership styles to influence his followers along the way of achieving the goal. Having considered the variety of situations and the diversity of employees' needs, House identified fourleaderbehaviors to apply during different stages of work: directive, supportive, participative and achievement-oriented.

1) Directive leadership style implies giving the subordinates the exact instructions and expecting from them the exact results; this style is useful when the nature of the task is not univocal.

2) Supportive style is characterized by the leader's attention to his followers' needs; it proves to be efficient when employees need to feel respected and needed for achieving the goals of the company.

3) Participative style means involving employees into the process of solving the company's problems. The boss shares all the available information on the subject with his employees and then utilizes their ideas and suggestions in the course of problem solving. This style is effective only when the employees are qualified and experienced, and they aim to be part of management and goal-achieving processes.

4) Achievement-oriented leadership style suggests setting a laborious goal which can be achieved only if the employees work to the extent of their abilities while the leader motivates them; this approach works only if the employees are willing to persevere in favor of great results and they are sure they can handle it.

The situational leadership model proposed by Hersey and Blanchard suggests four leadership styles and four follower maturity levels, which depend on the followers' education and experience, willingness to take responsibility for their actions, and the desire to accomplish the company's goals[22]. A leadership style should correspond with a maturity level for the purpose of getting the most productive leadership experience.

Style 1: Telling - is characterized by one-way communication in which the leader defines the roles of the individual or group and provides the what, how, why, when and where to do the task. The employees lack the specific skills required for the job in hand and are unable and unwilling to take responsibility for this job or task.

Style 2: Selling - while the leader is still providing the direction, he or she is now using two-way communication and providing the socio-emotional support that will allow the individual or group being influenced to buy into the process. The employees are unable to take on responsibility for the task being done; however, they are willing to work at the task. They are novice but enthusiastic.

Style 3: Participating - this is how shared decision-making about aspects of how the task is accomplished and the leader is providing fewer task behaviors while maintaining high relationship behavior. The subordinates are experienced and able to do the task but lack the confidence or the willingness to take on responsibility.

Style 4: Delegating - the leader is still involved in decisions; however, the process and responsibility has been passed to the individual or group. The leader stays involved to monitor progress. The subordinates are experienced at the task, and comfortable with their own ability to do it well. They are able and willing to not only do the task, but to take responsibility for the task.

\subsection{Integrated Psychological Theory}

The Integrated Psychological Theory of Leadership by J. Scouller(2011) had become an attempt to integrate the strengths of the older theories while addressing their limitations, largely by introducing a new element - the need for leaders to develop their leadership presence, attitude toward others and behavioral flexibility by practicing psychological 
mastery. It also offers a foundation for leaders wanting to apply the philosophies of servant leadership and authentic leadership. Designed as a practical tool for developing a person's leadership presence, knowhow and skill, Scouller'sThree Levels of Leadership model aims to summarize what leaders have to do, not only to bring leadership to their group or organization, but also to develop themselves technically and psychologically as leaders.

This model (alsoknownasthe « $3 \mathrm{P} »$ model)includes three levels of leadership. The two outer levels - public and private leadership - are what the leader must do behaviorally with individuals or groups to address the "four dimensions of leadership". These are:

1) a shared, motivating group purpose or vision;

2) action, progress and results;

3) collective unity or team spirit;

4) individual selection and motivation.

He listed 34 distinct "public leadership" behaviors and 14 "private leadership" behaviors. The inner level - personal leadership - refers to what leaders should do to grow their leadership presence, knowhow and skill. It has three aspects:

1) developing one's technical knowhow and skill;

2) cultivating the right attitude toward other people;

3) working on psychological self-mastery.

The idea is that if leaders want to be effective they must work on all three levels in parallel.Scouller argued that self-mastery is the key to growing one's leadership presence, building trusting relationships with followers and dissolving one's limiting beliefs and habits, thereby enabling behavioral flexibility as circumstances change, while staying connected to one's core values (that is, while remaining authentic). To support leaders' development, he introduced a new model of the human psyche and outlined the principles and techniques of self-mastery, which include the practice of mindfulness meditation. However, it may be difficult for some leaders to use this theory as a guide to selfdevelopment without the assistance of a professional coach or psychotherapist at some point as many of its ideas around self-mastery are deeply psychological [38].

\section{Leadership in the Construction Industry}

Market relations development in the construction industry arouses a demand for a modern approach to top management on national, industrial and local levels. Research in the construction industry begins to pay more attention to both project management and the role of leadership in the field. Current perception of construction project leaders is largely built around power, authority and task-orientation, which is not unexpected due to the traditional focus of the construction industry on technical and managerial features of construction projects. However, new challenges of the modern world and rapidly evolving business require a renewed understanding of leadership and a change in conventional notions of leadership in the construction industry.[32]

Due to the increased interest in project management, construction and development organizations are now looking for professionals who obtain not only technical knowledge, but better managerial and leadership skills. There is a need for specialists with transformational mentality, who are able to operate with a complex approach to leadership and an understanding of their actions, as the construction industry has an impact not only on the society's well-being, but on the environment as well.

Nonetheless, the construction industry still revolves around the current project management and the short run goal-achievement. This is probably the reason why construction project managers are perceived as managers in a literal sense of this word, rather than as leaders. They are bound to stay within the framework of the traditional triangle of key parameters of effectiveness: stick to the schedule, stay within the budget, do 
it according to a required level of quality. This standard approach becomes an obstacle on their way to become true leaders and to inspire their teams to achieve more. As a result, they are concentrated on the ultimate goal rather than the means of achieving it, which allows us to classify them as production-oriented rather than people-oriented. These managers operate by the book, managing their employees on a day-to-day basis, rather than solve long-run problems with more effective solutions.

The uniqueness of the construction industry, caused by final products' special features, makes project management a distinct subject with its own particular qualities: large infrastructure projects are being executed with participation of state, municipal and private sectors, where planning, financing and implementation are strictly regulated; globalization of construction leads to increased foreign participation in projects; increasing trend of strategic alliances such as joint ventures, consortia, mergers, acquisitions and partnering relationships. The real-life professional activity in the construction industry requires a considerable increase in quality of research, renewed training programs for future highquality specialists and a creation of human recourses system (teamwork, communication).Economic challenges include funding difficulties, uncertain economic conditions, threats of high inflation due to increased energy prices, fluctuating stock values and exchange rates, and cash flow problems. The main technological challenges lay in a gap between construction technology level in Russia and developed countries. There are difficulties with technological innovation transfer due to insufficient use of information and communication technology (ICT) such as in e-procurement. Legal and regulatory challenges include: different legal systems, litigation procedures, and arbitration methods within and across countries. Sustainability and environmental challenges also don't go unnoticed.

Everything mentioned above negatively affects further development of the construction industry, therefore there is a need for strong project leaders who are able to handle all the hurdles and lead the company to success [33].

\section{Results}

The research showed quite interesting results. For instance, it was found that team-oriented leaders were the most effective, while production-oriented managers scored the lowest of all. Those who used a compromise leadership style showed middle range effectiveness results [34]. Also it was found that construction managers displayed supportive style in feasibility study and pre-contract stages of works eventually transforming to directive styles as construction progressed [35].

There is no common opinion on which behavioral model suits best to construction project managers. Obviously, not one leadership style may be considered perfect for every situation anytime. Moreover, the majority of known leadership styles are centered on personality, on task, on relationships or on a change - analyzing these, it's impossible to know whether the leadership is authentic or not. People, representing themselves as leaders, may simply be changing hats for their own purposes.

There is a question if such aspects as task/relationship orientation, clarity of vision, intellectual stimulation, active/passive management, etc. are enough for leader's effectiveness evaluation. Most of these styles do not consider the reason why a leader would pick a particular style or how often he would change it for another one.

It is also unclear:

- why some leadership styles are working for one team but fail to be effective for another team in similar circumstances;

- how can a leader use several behavioral styles at the same time while working on different projects; 
- is it possible not to make an impression of an untrustworthy leader if he changes his behavioral style too often;

- is there an ideal set of traits which may be used as a basis for the perfect leadership style.

The answers to these questions may be found in the concept of «authentic leadership», introduced by F. Luthans, B.J. Avolio and al. It represents future-oriented, altruistic, selfregulatory leadership as a solution for modern management and leadership problems [36]. It emphasizes building the leader's legitimacy through honest relationships with followers, which value their input and are built on an ethical foundation. Authenticleadersarenotegocentricorstrictlyproduction-oriented;they are motivated by wellbeing of their subordinates, organization and society in common. They build a working space where prevail mutual trust, optimism, altruism and social transparency. These people obtain the highest level of integrity and responsibility, and, in the process of reaching goals they do not forget about their moral obligations before their clients, companies, society and future generations.

\section{Conclusion}

There is a demand for increasing the quality of project managers' education and leadership skills in order to move the construction industry forward. Further research in leadership's impact on the success of modern development companies of various scale is necessary. Studies can also be focused on the organizational context with categorization by type of organization (contractors, architects, designers, quantity surveyors and so on), size of organization (small, medium, large; local, multinational, and so on), and focus of organizational activity (civil engineering, industrial engineering, roads, and so on). This complex analysis may help us comprehend specific leadership needs and demands of organizations belonging to different contexts; and what influences the tactics leaders use to make a company more effective and successful.

\section{References}

1. R.Arvey, M.Rotundo, W.Johnson, Z.Zhang, M.McGue, The Leadership Quarterly 17, 1-20 (2006)

2. B.Bass, R.Riggio, Lawrence Erlbaum Associates Publishers, 26 (2006)

3. B.Bass, B.Avolio, L.Atwater, Applied Psychology 45, 5-34(1996)

4. W.Bennis, Addison-Wesley, 23 (1989)

5. R. Blake, J. Mouton, The Key to Leadership Excellence, 27 (1964)

6. J. Burns, Harper and Row Publishers Inc., 9(1978)

7. URL: http://www.businessballs.com/leadership-theories.htm\#integrated-psychologicalleadership

8. T.Carlyle, James Fraser, 10(1841)

9. M.Chemers, Earlbaum, 4(1997)

10. F. Fiedler, Harper and Row Publishers Inc., 57(1967)

11. R. Foti, N.Hauenstein, Journal of Applied Psychology 92 (2), 347-355(2007)

12. C.Fraser, Construction Management \& Economics 18(1), 29-36(2000)

13. J.Gardner, New York: Free Press(1990) 
14. W.Gardner, B.Avolio, F.Luthans, D. May, F.Walumba, The Leadership Quarterly16, 343-372(2005)

15. A. Hemphill, K. John, Ohio State University Bureau of Educational Research (1949)

16. P. Hersey, K. Blanchard, D.Johnson, Pearson Education, 9(2008)

17. R. House, Cornell University16 (3), 321-339(1971)

18. T.Judge, J.Bono, R.Ilies,M. Gerhardt, Journal of Applied Psychology 87 (4), 765-780 (2002)

19. J.Kickul, G.Neuman,Journal of Business and Psychology 15, 27-51(2000)

20. K. Lewin, R.Lippitt, R. White, Journal of Social Psychology 22, 271-301(1939)

21. R.Lord, C. Vader, G. Alliger, Journal of Applied Psychology 71(3), 402-410 (1986)

22. R.Mann, Psychological Bulletin 56 (4), 241-270(1959)

23. J.Maxwell, Thomas Nelson Inc, 6(1998)

24. R. MacLachlan, People Management magazine, 8 (2012)

25. S.Rowlinson, T. Ho, P.Yun, Construction Management and Economics 11, 455465(1993)

26. J.Schaub, K.Pavlovic, Engineering Professionalism and Ethics, 37(1983)

27. J.Smith, R.Foti, Leadership Quarterly 9 (2), 147-160(1998)

28. J. Spillane, J. Diamond, of Curriculum Studies 36 (1), 3-34 (2004)

29. R.Stogdill, Journal of Psychology 25, 35-71(1948)

30. R.Stogdill,New York: Free Press, 11(1982)

31. S.Tagger, R.Hackett, S. Saha, Personnel Psychology 52 (4), 899-926(1999)

32. S.Toor, G.Ofori, International Journal of Project Management 26, 620-630 (2008)

33. S.Toor, G.Ofori, National University of Singapore, 33 (2004)

34. K. Van Wormer, F. Besthorn, T. Keefe, Oxford University Press, 27 (2007)

35. V.Vroom, A.Jago, American Psychologist 62(1), 17-24(2007)

36. V. Vroom, P. Yetton, University of Pittsburgh Press, 28(1973)

37. S.Zaccaro,American Psychologist 62 (1), 6-16(2007)

38. M.Petrakov, A.Bolshakova, Modern recruiting tendencies 20, 371-375 (2004) 